\title{
Are the Obese Patients and Patients with Severe Malnutrition at Increased Risk of Severe Coronavirus Disease 2019 during Hospital Admission?
}

\author{
Zorica Markovska ${ }^{1}$, Dragan Mijakoski ${ }^{2,3 *}$, Katerina Kuzmanova ${ }^{4}$, Iskra Meshkova ${ }^{1}$, Ivana Tusheva ${ }^{5}$, Sasho Stoleski ${ }^{2,3}$ \\ ${ }^{1}$ Department of Anesthesiology and Intensive Care, City General Hospital $8^{\text {th }}$ September, Skopje, Republic of Macedonia; \\ ${ }^{2}$ Department of Allergy, Institute of Occupational Health of RM, Skopje, Republic of Macedonia; ${ }^{3}$ Department of Occupational \\ Medicine, Faculty of Medicine, Ss. Cyril and Methodius University in Skopje, Skopje, Republic of Macedonia; ${ }^{4}$ Department of \\ Anesthesiology and Intensive Care, City General Hospital, Strumica, Republic of Macedonia; ${ }^{5}$ Department of Dermatology, City \\ General Hospital $8^{\text {th }}$ September, Skopje, Republic of Macedonia
}

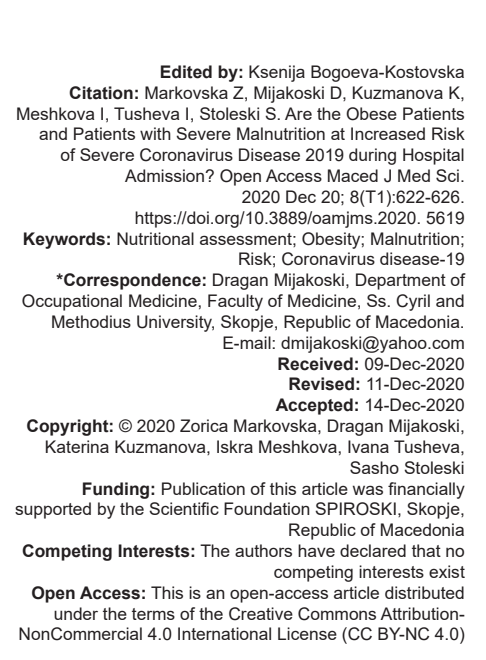

\section{Abstract}

BACKGROUND: Recently, authorities highlighted the need for nutritional management of individuals with severe acute respiratory syndrome coronavirus 2 infection.

AIM: The aim of the study was to evaluate the use of body mass index (BMI) and nutrition risk index (NRI) on hospita admission for detecting patients at risk for malnutrition and obesity and their association with patients' outcomes (disease type, length of hospital and home stay, and inflammatory markers).

METHODS: The study of 100 patients with confirmed diagnosis Coronavirus Disease-19 (COVID-19). Assessment of patients took place at City General Hospital $8^{\text {th }}$ September, Skopje, transformed into main COVID-19 Center during pandemic. Primary outcomes were NRI and BMI scores, while secondary ones: length of home and hospital stay, number of symptoms, presence of co-morbidities, type of disease, serum albumin, and C-reactive protein (CRP).

RESULTS: Patients were classified according to BMI and NRI scores. Increased BMI and NRI were associated with a severe type of disease. Most of the patients with severe disease were: obese $(83.3 \%)$ and patients with risk for malnutrition (53.3\%). Obese patients had a longer length of home stay and higher CRP levels, but the level of albumin was lower in a group with a risk for malnutrition.

CONCLUSION: Future studies are needed to identify and quantify specific screening tool for nutrition deficiency in patients with COVID-19 infection.

\section{Introduction}

On the April 12, 2020, Macedonian health authorities reported 854 people with severe acute respiratory syndrome coronavirus 2 (SARS-CoV-2) infection. Few months later, coronavirus disease-2019 (COVID-19) is still a major health challenge for healthcare workers. Symptoms, laboratory, and radiology findings are the main targets of diagnosis [1]. Recently, European Society for Clinical Nutrition and Metabolism (ESPEN) published practical guidance for nutritional management of individuals with SARS-CoV-2 infections [2]. Hospitalized patients are at high risk of obesity or malnutrition upon hospital admission, even in the absence of chronic disease [3], [4], [5]. The underlying disease may directly decrease the dietary intake and to impair the appetite [6]. Furthermore, increased metabolism due to the stress of acute disease results in immune dysfunction, loss of fat-free mass and can lead to further inadequate dietary intake and deterioration of patients, as well as their nutritional status.

Nutrition deficiency represented by malnutrition and obesity, also, adversely affect clinical outcomes: Complications, length of stay (LOS), and mortality [7]. Nutritional deficiency is preventable and mostly reversible with adequate nutritional therapy. Therefore, it is important to perform nutrition risk screening systematically in all patients at the hospital admission in order to find those patients who are at risk. At present, there is no universally accepted gold standard for the assessment of nutrition status [8].

There are at least 33 different screening tools for nutrition risk [9]. In the present study, we applied two of them, namely nutrition risk index (NRI) and body mass index (BMI). We also measured serum albumin in each patient.

$\mathrm{NRI}$ is an easily applicable tool for detecting protein depletion. We can use this formula for its determination: 
$\mathrm{NRI}=1.519 \times$ serum albumin in $\mathrm{g} / \mathrm{L}+(41.7 \times$ present weight in $\mathrm{kg} / \mathrm{usual}$ weight in $\mathrm{kg}$ )

For easier analysis, the calculator by Buzby can be used for its calculation.

$\mathrm{BMI}$ is calculated as the patient's weight in $\mathrm{kg}$ divided by the square of her/his height in meters.

We hypothesized that nutrition changes because of an acute illness or inadequate intake would affect the length of hospital stay LOS and the type of the disease.

\section{Aim}

The aim of this study was to evaluate the use of nutrition screening tools: BMI and NRI on hospital admission for detecting patients at risk for malnutrition and obesity and their association with patients' outcomes (type of disease, length of hospital and home stay, and inflammatory markers). Nutrition status of the patients was categorized into no risk and severe risk of malnutrition according to NRI. According to BMI, the patients were divided into either the normal group or in obese group. The actual study was a prospective observation study analyzing the need for evaluation of patients' nutrition status on hospital admission in City General Hospital $8^{\text {th }}$ September in Skopje, Macedonia. We also wanted to assess whether the patients were obese or malnourished on hospital admission. Ethics approval was obtained by the Ethics Committee for the emerging infection of the hospital.

\section{Patients and Methods}

Nutrition screening tools were implemented in the COVID-19 Emergency Unit in City General Hospital $8^{\text {th }}$ September in Skopje to enable screening of the nutritional status. A group of 100 adult patients affected by SARS-CoV-2 infection (aged $59 \pm 60$ years). A diagnosis of COVID-19 was confirmed according to the following criteria: History of epidemiological exposure, clinical symptoms of COVID-19-like pneumonia, positive result of a polymerase chain reaction (PCR) test, and pulmonary imaging changes with ground glass infiltration or consolidation. Our hospital become the main regional COVID-19 hospital in Macedonia and it was designed to accept all susceptive cases of COVID-19, but only patients with the confirmed diagnosis have been included in the study. Patients were analyzed at the hospital admission for demographics data, type (severity) of disease, symptoms, and co-morbidities.

Body fat and protein assessment were performed within $48 \mathrm{~h}$ of admission using measure of height and weight, as well as specific proteins in serum: albumin, globulin, and total proteins. Nutrition and dietary status of each patient were assessed by BMI, NRI, and serum levels of albumins and total proteins. NRI was calculated by an online calculator (https://www.mdcalc. com/nutritional-risk-index-nri) using serum albumin and recent body weight. BMI was also calculated using online calculator (https://www.calculator.net/bmi-calculator. html), entering patients' weight and height.

According to the NRI values, patients were classified into two groups: Nutritional risk group $(\mathrm{NRI}<83.5)$ and normal group without severe risk (NRI 283.5). According to the BMI, patients were classified into: Normal group (BMI $\leq 25$ ), pre-obesity, and obese group, respectively. Pre-obesity and obese groups were merged into one group (BMI >25). Inflammatory status was also assessed within $48 \mathrm{~h}$ of admission using laboratory markers CPR and globulin. Lengths of hospital and home stay were filled latter, after hospitalization using medical records.

\section{Results}

A total number of 100 patients with COVID-19 were enrolled in the study. Patients' characteristics according to BMI groups are shown in Table 1.

There was no difference between the two BMI groups according to age $(t=-0.073, p=0.942)$, gender $\left(\chi^{2}=2.979, p=0.084\right)$, presence of co-morbidities $\left(\chi^{2}=0.004, p=0.948\right)$, level of albumin $(t=0.102$, $\mathrm{p}=0.919)$, and number of symptoms $(\mathrm{t}=-0.18$, $p=0.857)$. Significantly more obese patients were detected in the group with severe COVID-19 (83.3\%) than in the group with mild COVID-19 $(53.2 \%)\left(\chi^{2}=7.583\right.$, $p=0.023)$. The length of hospital stay was longer in the group with normal BMI $(15.09 \pm 10.19$ vs. $11.33 \pm$ $5.97)$, but the difference was not significant $(t=1.981$, $p=0.054)$. The length of home stay before hospitalization was longer in the group with obese patients $(4.73 \pm 4.4$ vs. $2.88 \pm 2.68)(t=-2.217, p=0.029)$. The level of C-reactive protein (CRP) was significantly higher in obese patients $(130.14 \pm 80.6)$ than in group with normal BMI $(88.11 \pm 63.79)(t=-2.643, p=0.006)$.

Patients' characteristics according to NRI groups are shown in Table 2.

Table 2 demonstrates significant differences between groups of patients with different risk for malnutrition, where the group of patients with severe risk for malnutrition ( $\mathrm{NRI}<83.5)$ had significantly lower levels of albumin $(24.01 \pm 3.48$ vs. $31.91 \pm 3.81)$ $(t=10.68, p<0.001)$ and total proteins $(64.42 \pm 5$ vs. $67.37 \pm 5.78)(t=2.69, p=0.008)$, as well as significantly higher level of globulin $(40.2 \pm 5.75$ vs. $35.87 \pm 5.8)$ $(\mathrm{t}=-3.709, \mathrm{p}<0.001)$.

Table 3 shows the correlation coefficient between BMI and NRI. 
Table 1: Patients' characteristics according to BMI groups

\begin{tabular}{|c|c|c|c|}
\hline Variable & Normal group BMI $\leq 25(n=34)$ & Obese group BMI>25 $(n=66)$ & Statistic, $p$-value \\
\hline Age (years) (mean $\pm \mathrm{SD})$ & $59.68 \pm 16.43$ & $59.91 \pm 11.83$ & $t=-0.073, p=0.942$ \\
\hline \multicolumn{4}{|l|}{ Gender - $\mathrm{n}(\%)$} \\
\hline Male $(n=65)$ & $26(40)$ & $39(60)$ & \multirow[t]{2}{*}{$\chi^{2}=2.979, p=0.084$} \\
\hline Female $(n=35)$ & $8(22.9)$ & $27(77.1)$ & \\
\hline \multicolumn{4}{|l|}{ Type of disease - $n(\%)$} \\
\hline Mild $(n=47)$ & $22(46.8)$ & $25(53.2)$ & \multirow[t]{3}{*}{$\chi^{2}=7.583, p=0.023$} \\
\hline Moderate $(n=23)$ & $7(30.4)$ & $16(69.6)$ & \\
\hline Severe $(n=30)$ & $5(16.7)$ & $25(83.3)$ & \\
\hline With co-morbidities - $\mathrm{n}(\%)$ & $24(70.6)$ & $47(71.2)$ & $\chi^{2}=0.004, p=0.948$ \\
\hline Length of hospital stay (days) (mean $\pm \mathrm{SD}$ ) & $15.09 \pm 10.19$ & $11.33 \pm 5.97$ & $t=1.981, p=0.054$ \\
\hline Length of home stay before hospitalization (days) (mean $\pm S D$ ) & $2.88 \pm 2.68$ & $4.73 \pm 4.4$ & $t=-2.217, p=0.029$ \\
\hline Albumin (mean $\pm \mathrm{SD})(\mathrm{g} / \mathrm{L})$ & $28.26 \pm 6.02$ & $28.15 \pm 5.06$ & $t=0.102, p=0.919$ \\
\hline Globulin (mean $\pm \mathrm{SD}$ ) $(\mathrm{g} / \mathrm{L})$ & $37.64 \pm 5.67$ & $38.17 \pm 6.33$ & $\mathrm{t}=-0.404, \mathrm{p}=0.687$ \\
\hline Total proteins (mean $\pm \mathrm{SD})(\mathrm{g} / \mathrm{L})$ & $65.96 \pm 4.37$ & $66.13 \pm 6.21$ & $t=-0.152, p=0.880$ \\
\hline Number of symptoms & $2.44 \pm 1.11$ & $2.48 \pm 1.17$ & $\mathrm{t}=-0.18, \mathrm{p}=0.857$ \\
\hline $\mathrm{CRP}($ mean $\pm \mathrm{SD})(\mathrm{mg} / \mathrm{L})$ & $88.11 \pm 63.79$ & $130.14 \pm 80.6$ & $\mathrm{t}=-2.643, p=0.006$ \\
\hline
\end{tabular}

Table 2: Patients' characteristics according to NRI groups

\begin{tabular}{|c|c|c|c|}
\hline Variable & $\begin{array}{l}\text { Not severe risk for malnutrition } \\
(N R I \geq 83.5)(n=51)\end{array}$ & $\begin{array}{l}\text { Severe risk for malnutrition } \\
(N R I<83.5)(n=47)\end{array}$ & Statistic, $p$-value \\
\hline Age (years) (mean $\pm \mathrm{SD})$ & $60.2 \pm 13.38$ & $59.19 \pm 13.96$ & $t=0.364, p=0.717$ \\
\hline \multicolumn{4}{|l|}{ Gender- $n(\%)$} \\
\hline Male $(n=63)$ & $36(57.1)$ & 27 (42.9) & \multirow[t]{2}{*}{$\chi^{2}=1.840, p=0.175$} \\
\hline Female $(n=35)$ & $15(42.9)$ & $20(57.1)$ & \\
\hline \multicolumn{4}{|l|}{ Type of disease - $\mathrm{n}(\%)$} \\
\hline Mild $(n=45)$ & $27(60)$ & $18(40)$ & \multirow[t]{3}{*}{$\chi^{2}=2.165, p=0.339$} \\
\hline Moderate $(n=23)$ & $10(43.5)$ & $13(56.5)$ & \\
\hline Severe $(n=30)$ & $14(46.7)$ & 16 (53.3) & \\
\hline With co-morbidities - n (\%) & 40 (78.4) & $30(63.8)$ & $\chi^{2}=2.555, p=0.110$ \\
\hline Length of home stay before hospitalization (days) (mean $\pm \mathrm{SD}$ ) & $4.38 \pm 3.17$ & $3.66 \pm 4.71$ & $t=0.866, p=0.389$ \\
\hline Albumin $($ mean $\pm \mathrm{SD})(\mathrm{g} / \mathrm{L})$ & $31.91 \pm 3.81$ & $24.01 \pm 3.48$ & $t=10.68, p<0.001$ \\
\hline Globulin (mean $\pm \mathrm{SD}$ ) (g/L) & $35.87 \pm 5.8$ & $40.2 \pm 5.75$ & $t=-3.709, p<0.001$ \\
\hline Total proteins (mean $\pm \mathrm{SD}$ ) (g/L) & $67.37 \pm 5.78$ & $64.42 \pm 5$ & $t=2.69, p=0.008$ \\
\hline Number of symptoms & $2.37 \pm 1.18$ & $2.55 \pm 1.12$ & $t=-0.775, p=0.440$ \\
\hline $\mathrm{CRP}($ mean $\pm \mathrm{SD})(\mathrm{mg} / \mathrm{L})$ & $118.57 \pm 78.5$ & $113.66 \pm 78.7$ & $t=0.309, p=0.758$ \\
\hline
\end{tabular}

Graphical representation of the correlation between $\mathrm{BMI}$ and $\mathrm{NRI}$ is shown in Figure 1.

Table 3: Analysis of correlation between BMI and NRI

\begin{tabular}{llll}
\hline Bivariate analysis & BMI & NRI & p-value \\
\hline BMI & 1 & $0.303^{*}$ & 0.002 \\
\hline${ }^{*}$ Pearson r; BMI: Body mass index; NRI: Nutrition risk index. & &
\end{tabular}

Previous table and graph demonstrate a significant positive correlation between BMI and NRI $(r=0.303, p=0.002)$, or higher the BMI, higher the NRI.

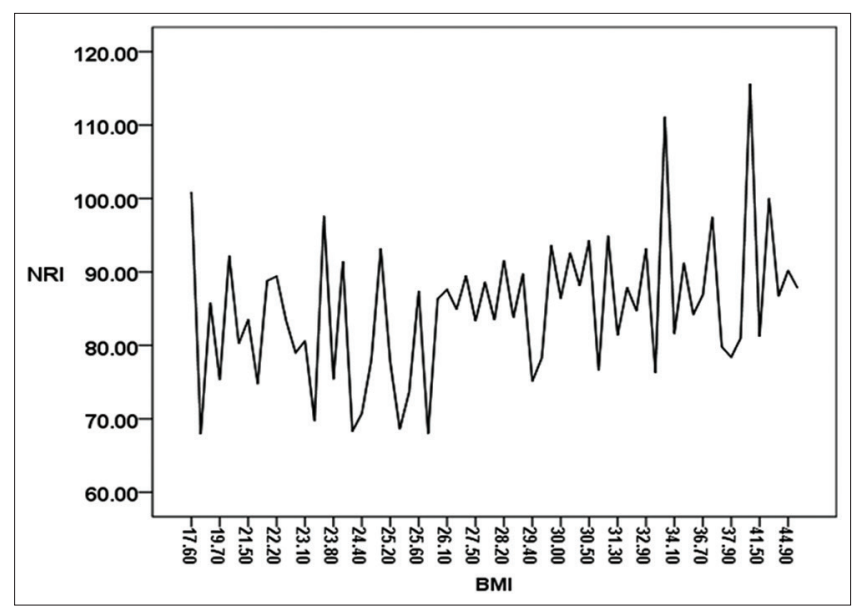

Figure 1: Graphical representation of the correlation between body mass index and nutrition risk index

Results of our study are showing that obese patients impose a higher risk for worse outcome according to the findings that significantly more obese patients were detected in the group with severe COVID-19, the length of home stay was longer in obese patients, and the level of CRP was significantly higher in this group of patients. Despite the detected correlation between $\mathrm{BMI}$ and $\mathrm{NRI}$, we have found that there were no significant associations between NRI and other variables analyzed.

\section{Discussion}

ESPEN emphasizes the need to manage the diet of patients with COVID-19 infection. Inadequate dietary intake is one of the main reasons for the increased risk of infection [10]. Furthermore, inadequate dietary intake can lead to rapid obesity or malnutrition [11], [12]. Malnutrition and obesity are common findings of hospital dependencies for surgical patients [13], but the situation with patients infected with COVID-19 is unclear, especially if the patient has severe symptoms. Some studies demonstrated that obesity measured as BMI, and malnutrition defined as hypoalbuminemia or decline of serum albumin, were associated with an increased risk of developing severe pneumonia in COVID-19 [14], [15], [16].

The reported incidence of a severe type of disease of the patients in our study was 30\%. Our data also showed that obese and NRI risk group patients had a severe type of disease in respect to non-obese and normal NRI group. 
In the course of severe progress of COVID-19, the major component is hyper-inflammation [17]. Many nutrients have a role in supporting the immune system to defend against pathogens. Hence, regarding to COVID19 infection, it is important to evaluate the nutrition status of each patient. Furthermore, nutrition deficiency needs to be considered in severe cases of COVID-19.

Body fat is biologically active and a source of pro-inflammatory factors, so bone marrow infection leads to a further increase in the production of proinflammatory cytokines [18]. In our study, even the normal BMI group showed an incidence of increased CRP. In patients classified according to NRI, the CRP was almost identical. It was, therefore, difficult to conclude whether malnutrition was a result of inflammation alone and not of inadequate dietary intake. However, given the significant reduction in albumin and high BMI, malnutrition is thought to be related to the severity of COVID-19. Further studies are needed to determine the screening tool to detect the cause of malnutrition.

Many studies have aimed to predict the number of hospital beds required for COVID-19 [19].

Several studies have shown a close relationship between LOS and dietary status [20], [21], [22]. In our study, the risk group had a longer LOS compared to those who were not at risk. Among obese patients, LOS at home before hospitalization was longer than that of patients with a normal BMI. This suggests that obesity affects breathing difficulties even before inflammation sets in [23]. Due to obesity, the patient always had difficulty breathing. His/her dyspnea he/she thought that was related to obesity and not to COVID-19 infection. We suppose that this is the reason why he/she is consulting the physician later on. Further research is needed, including other factors, such as demographics, laboratory analyses, and particularly the LOS at home.

In our study, increased BMI was associated with a higher disease rate, longer stay at home, and higher CRP levels. In contrast, no difference was observed between the two BMI groups for albumin level and number of symptoms. Increased NRI was associated with a serious form of the disease, longer hospital stay, and lower albumin levels. There appears to be a slight difference in CRP seen in a group of patients at different risk of malnutrition.

Our study has some limitations, but the fact that our hospital was the Main Regional COVID-19 Center brought us pleasure because we have the opportunity to collect data and to be the first to do that in the country.

Patients very often came late in the course of their illness, so they were not included because their weight and height could not be measured. When we collected the data retrospectively, we could not get all the information. For example, a patient due to respiratory discomfort, he/she refused to talk about eating properly, or LOS was affected by the PCR test results, even if he/ she felt well.

\section{Conclusion}

$\mathrm{BMI}$ and NRI are well-established screening tools for the assessment of nutritional status on hospital admission. Nutritional care plans should be developed and implemented to maintain and improve patients nutritional status. This study opened the question: Can we manage the acute illness easily with a better outcome if patients' examination starts with nutrition assessment, initially? Further investigations are also needed for the factors affecting the length of home stay, especially during a pandemic when the number of hospital beds is limited and the number of patients rapidly increases.

\section{References}

1. Kakhki RK, Kakhki MK, Neshani A. COVID-19 target: A specific target for novel coronavirus detection. Gene Rep. 2020;20:100740. https://doi.org/10.1016/j.genrep.2020.100740 PMid:32510005

2. Barazzoni R, Bischoff SC, Breda J, Wickramasinghe $\mathrm{K}$, Krznaric Z, Nitzan D, et al. ESPEN expert statements and practical guidance for nutritional management of individuals with SARS-CoV-2 infection. Clin Nutr. 2020;39(6):1631-8. https://doi org/10.1016/j.clnu.2020.03.022

PMid:32305181

3. D'Onofrio K. Malnutrition is Common at Hospital Admission and Pre-Discharge. Available from: https://www.docwirenews.com/ health-and-wellness/diet/malnutrition-hospital-admission. [Last accessed on 2020 Sep 20].

4. Schafer MH, Ferraro KF. Obesity and hospitalization over the adult life course: Does duration of exposure increase use? J Health Soc Behav. 2007;48(4):434-49. https://doi. org/10.1177/002214650704800407

PMid:18198689

5. Volkert D, Beck AM, Cederholm T, Cruz-Jentoft A, Goisser S, Hooper L, et al. ESPEN guideline on clinical nutrition and hydration in geriatrics. Clin Nutr. 2019;38(1):10-47. https://doi. org/10.1016/j.clnu.2018.05.024

PMid:30005900

6. Sobotka L. Nutritional support in geriatric patients: The ESPEN new recommended guidelines. Vnitr Lek. 2018;64(11):1053-8. PMid:30606021

7. Naveed S, Mclnnes IB, McMurray JJ. Obesity a risk factor for sever COVID-19 infection; multiple potential mechanisms. Circulation. 2020;142:4-6. https://doi.org/10.1161/ circulationaha.120.047659

8. Donini LM, Savina C, Rosano A, Cannella C. Systematic review of nutritional status evaluation and screening tools in the elderly. J Nutr Health Aging. 2007;11(5):421-32.

PMid:17657364

9. Van Bokhorst-de van der Schueren MA, Guaitoli PR, Jansma EP, De Vet HC. Nutrition screening tools: Does one size fit all? A systematic review of screening tools for the hospital setting. Clin Nutr. 2014;33(1):39-58. https://doi.org/10.1016/j. clnu.2013.04.008

PMid:23688831 
10. Farhadi S, Ovchinnikov RS. The relationship between nutrition and infectious diseases: A review. Biomed Biotechnol Res J. 2018;2(3):168-72.

11. Romieu I, Dossus L, Barquera $S$, Blottière HM, Franks PW, Gunter M, et al. Energy balance and obesity: What are the main drivers? Cancer Causes Control. 2017;28(3):247-58. https://doi. org/10.1007/s10552-017-0869-z

PMid:28210884

12. Saunders $\mathrm{J}$, Smith T. Malnutrition: Causes and consequences. Clin Med (Lond). 2010;10(6):624-7.

PMid:21413492

13. Kahokehr AA, Sammour T, Wang K, Sahakian V, Plank LD, Hill AG. Prevalence of malnutrition on admission to hospital-acute and elective general surgical patients. Eur J Clin Nutr Metab. 2010;5(1):e21-5. https://doi.org/10.1016/j.eclnm.2009.11.001

14. Petrili CM, Jones SA, Yang J, Rajagopalan H, O'Donnell L, Chernyak $\mathrm{Y}$, et al. Factors Associated with Hospitalization and Critical Illness among 4103 Patients with COVID-19 Disease in New York City. New York: medRixiv; 2020. https://doi. org/10.1101/2020.04.08.20057794

15. Guan WJ, Zhong NS. Clinical characteristics of COVID-19 in China. N Engl J Med. 2020;382(19):1861-2. PMid:32220206

16. Zhou F, Yu T, Du R, Fan G, Liu Y, Liu Z, et al. Clinical course and risk factors for mortality of adult in patients with COVID-19 in Wuhan, China: A retrospective cohort study. Lancet. 2020;395(10229):1054-62. https://doi.org/10.1016/ s0140-6736(20)30566-3 PMid:32171076

17. Manson JJ, Crooks C, Naja M, Ledlie A, Goulden B, Liddle T, et al. COVID-19-associated hyperinflammation and escalation of patient care: A retrospective longitudinal cohort study. Lancet
Rheumatol. 2020;2(10):e594-602.

PMid:32864628

18. Kwaifa IK, Bahari H, Yong YK, Noor SM. Endothelial dysfunction in obesity-induced inflammation: Molecular Mechanisms and clinical implications. Biomolecules. 2020:10(2):E291. https://doi. org/10.3390/biom10020291 PMid:32069832

19. Gastro MC, Carvalho LR, Chin T, Kahn R, Franca GV, Macario EM, et al. Demand for Hospitalization Services for COVID-19 Patients in Brazil. New York: medRxiv; 2020. https:// doi.org/10.1101/2020.03.30.20047662

20. Pichard C, Kyle UG, Morabia A, Perrier A, Vermeulen B, Unger P. Nutritional assessment: Lean body mass depletion at hospital admission is associated with an increased length of stay. Am J Clin Nutr. 2004;79(4):613-8. https://doi.org/10.1093/ ajcn/79.4.613

PMid:15051605

21. Pirlich M, Schütz T, Norman K, Gastell S, Lübke HJ, Bischoff SC et al. The German hospital malnutrition study. Clin Nutr. 2006;25(4):563-72. https://doi.org/10.1016/j.clnu.2006.03.005 PMid:16698132

22. Allard JP, Keller H, Jeejeebhoy KN, Laporte M, Duerksen DR, Gramlich L, et al. Malnutrition at hospital admission-contributors and effect on length of stay: A prospective cohort study from the Canadian malnutrition task force. JPEN J Parenter Enteral Nutr. 2016;40(4):487-97. https://doi.org/10.1177/0148607114567902 PMid:25623481.

23. Tartof SY, Qian L, Hong V, Wei R, Nadjafi RF, Fischer H, et al. Obesity and mortality among patients diagnosed with COVID19: Results from an integrated health care organization. Ann Intern Med. 2020;173(10):773-81. http://doi:10.7326/ M20-3742 